\title{
ANÁLISE TEMPORO-ESPACIAL DO ESTADO DE CONSERVAÇÃO DA SERRA DE MARANGUAPE-CE
}

\author{
ANALYSIS TIME AND SPACE THE STATE OF CONSERVATION \\ MARANGUAPE -CE SAW
}

\author{
BRAGA ${ }^{1}$, D. P.; SOUZA ${ }^{2}$, M.J.N.; SOUZA ${ }^{1}$, G. M.; GOMES ${ }^{2}$, A. C..A. SILVA² ${ }^{2}$ G. M. \\ danielpauloknd@gmail.com;
}

\begin{abstract}
Resumo
A Serra de Maranguape carrega características físiconaturais que a inserem no contexto dos enclaves úmidos do semiárido cearense. Logo, o trabalho em epígrafe busca compreender quais as condições de conservação da biomassa na referida Serra, bem como, identificar o Índice de vegetação da Serra de Maranguape nos anos de 1991, 2001 e 2015, correlacionando-os com o total pluviométrico de cada período estudado. A Metodologia embasou-se na análise integrada do ambiente, dada a pertinência e eficácia que a mesma obtém em fazer conhecer a realidade ambiental dos sistemas naturais, soma-se a isso os procedimentos operacionais onde utilizou-se de levantamento bibliográfico pertinente, visita em campo e as geotecnologias mediante o ferramental de geoprocessamento com destaque aos softwares livres: QGis e Spring. Os resultados encontram-se materializados através de mapas e gráficos que possibilitaram embasar a discussão que o referido artigo se propõe. Portanto, a análise temporo-espacial do estado de conservação da Serra de Maranguape demonstrou que a mesma se encontra em processo de recuperação de sua cobertura vegetal.
\end{abstract}

Palavras-chave: Maranguape, Conservação. NDVI.

\begin{abstract}
The Maranguape Saw carries physical-natural characteristics that fall within the context of the humid enclaves of Ceará semiarid region. Soon the work epigraph seeks to understand what the biomass storage conditions in said Saw, as well as identify the Saw Vegetation Index Maranguape in 1991, 2001 and 2015, correlating them with the total rainfall of each period studied. The methodology has been based on integrated environmental analysis, given the relevance and effectiveness that it gets to make known the environmental reality of natural systems, adds to that operating procedures which made use of relevant literature, visit field and geotechnology by the tools of GIS with emphasis on free software: QGIS and Spring. The results are delivered through maps and charts that enabled base the discussion that that article is proposed. Therefore, the temporo-spatial analysis of the conservation status of Maranguape Saw demonstrated that it is in recovery process of vegetation.
\end{abstract}

Keywords: Maranguape, Conservation . NDVI.

\section{INTRODUÇÃOO}

No contexto do semiárido cearense, as serras úmidas são um destaque, pois apresentam todo um conjunto de fatores diferenciados seja hidro climáticos, seja pedológico e fitoecológicos, porém atualmente estes enclaves sofrem uma forte descaracterização ambiental ocasionada por um uso e ocupação desordenado.

Souza (2000) informa sobre as mudanças ambientais que exibem características alarmantes trazendo sérios prejuízos para os recursos naturais. Essas mudanças partem da ação humana sem

\footnotetext{
${ }^{I}$ Daniel Paulo Braga, graduando do curso de Geografia/Bacharelado, vinculado ao Laboratório de geoprocessamento e estudos aplicados da, Universidade Estadual do Ceará, Fortaleza -CE, Brasil.

${ }^{2}$ Marcos José Nogueira de Souza, doutor em Geografia, coordenador do Laboratório de Geografia Física e Estudos Ambientais e professor títular da Universidade Estadual do Ceará- UECE, Fortaleza-CE, Brasil.

${ }^{3}$ Guilherme Marques e Souza, doutorando do Programa de Pós-graduação em Geografia da Universidade Estadual do Ceará, Fortaleza-Ce, Brasil.

${ }^{4}$ Ana Carla Alves Gomes, mestranda do Programa de Pós-graduação em Geografia da Universidade Estadual do Ceará, Fortaleza-

${ }^{5}$ Gislania de Meneses Silva, graduanda do curso de Geografia/Bacharelado, vinculada ao Laboratório de Geoprocessamento e Estudos Aplicados da Universidade Estadual do Ceará, Fortaleza-CE, Brasil.
} 
planejamento e estudos sobre impactos ambientais, trazendo como consequência os processos de degradação em diferentes níveis.

A importância desse trabalho parte de mensurar o nível de conservação das áreas remanescentes da Mata Atlântica no ambiente serrano situadas no semiárido, as quais foram e ainda são descaracterizadas pelas intensas atividades antrópicas, em especial no objeto de estudo da referida pesquisa, a saber, a Serra de Maranguape. Essa Vegetação, atua como reguladora do fluxo dos mananciais hídricos, asseguram a fertilidade do solo, interferem no clima, protegem escarpas e encostas das serras e preservam um patrimônio histórico e cultural. Neste contexto, convém destacar a importância desse enclave úmido no domínio morfoclimático das caatingas do Nordeste Brasileiro.

A serra de Maranguape está localizada no estado do Ceará (Figura 01), compreendendo os municípios de Maranguape, Maracanaú e Caucaia dentro da Região Metropolitana de Fortaleza (RMF), a uma distância de aproximadamente $30 \mathrm{~km}$ da capital cearense, possuindo uma área de 318,69 km² e altitudes que chegam até 920 metros (SOUZA; OLIVEIRA, 2006).

Caracterizada geomorfologicamente como um maciço residual pré-litorâneo, destaca-se topograficamente entre a depressão sertaneja e a superfície dos tabuleiros pré-litorâneos. Souza (2000), no estudo geomorfológico do Ceará, incorpora-a no Domínio dos Escudos e Maciços Antigos, constituídos por rochas do embasamento cristalino, oriundas do Pré-Cambriano.

A serra possui disposição NE-SW e exibe marcas muito nítidas de oscilações climáticas úmidas e secas. Esses maciços úmidos ocorrem pontilhados no Estado, a saber, juntamente com as serras de Uruburetama, Baturité, Aratanha, Meruoca; as quais possuem condições hidroclimáticas com solos férteis e produtivos, configurando-se, portanto, um ambiente de exceção, enclaves de matas úmidas. Constituem-se verdadeiras "ilhas verdes" que recobrem as depressões interplanálticas e intermontanas semiáridas (AB'SABER,1974). 


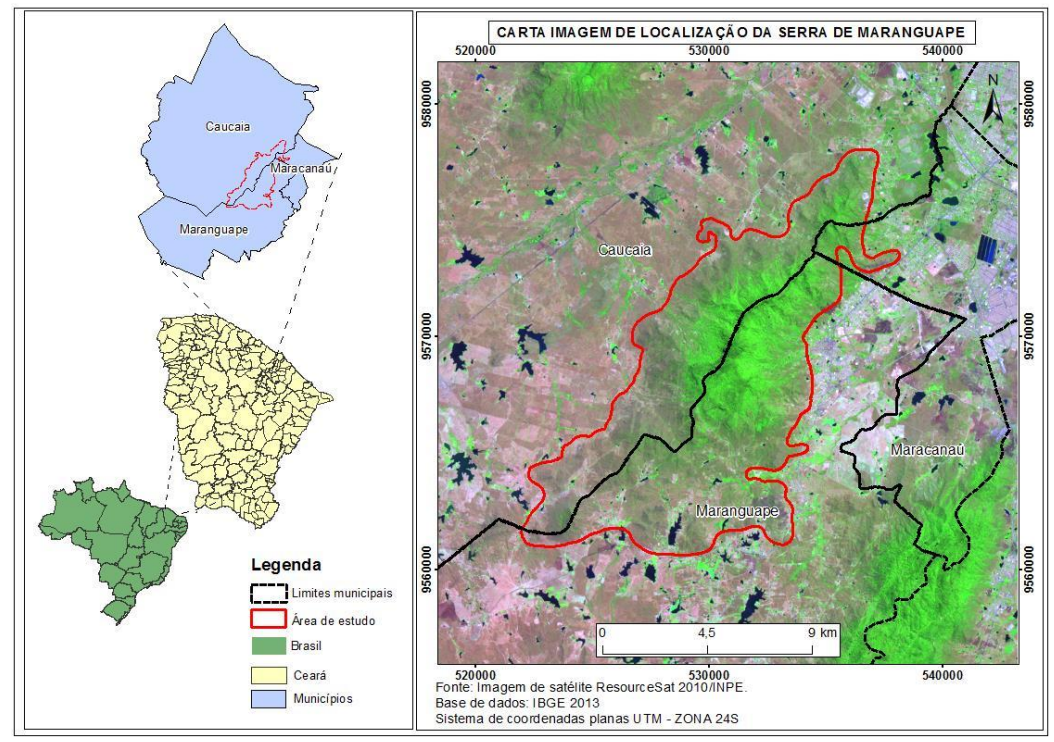

Figura 01: Carta imagem de localização da Serra de Maranguape.

Fonte: Autor, 2016

O clima determinante da área segundo o sistema de Thonthwaite é mesotérmico, quente e úmido com chuvas de verão e precipitações máximas de outono Ceará (2002). Alguns dos fatores que justificam e possibilitam as características climáticas nesse ambiente de exceção são: a ação combinada da posição geográfica próxima ao mar, a sua elevação topográfica que recebendo a influência das massas úmidas oriundas do oceano, interferindo diretamente no aumento da pluviometria e da umidade, ocasionando a diminuição da temperatura média e da evapotranspiração, atuando como barlavento, na porção norte oriental, conforme Ceará (2002).

Devido à elevada pluviosidade na área, a Serra de Maranguape apresenta-se como um pequeno dispersor de drenagem, que se orienta para o rio Ceará, a oeste, e para o rio Maranguapinho, a leste (CEARÁ, 2002). As redes hidrográficas possuem padrões subdendríticos, eventualmente subparalelos e angulares, escavando vales em formas de "V". Isto ocorre devido à impermeabilidade dos terrenos cristalinos aliados ao acentuado grau de dissecação do relevo.

Os solos encontrados na serra de Maranguape integram duas classes de evolução pedológicas: solos profundos (de 1 a 2 metros) com expressiva evolução pedogenética compreendendo os Argissolos Vermelho-Amarelos, e os Neossolos Litólicos Eutróficos, solos rasos (inferior a $50 \mathrm{~cm}$ ) caracterizados por não concluírem o processo pedogenético, conforme o novo Sistema Brasileiro de Classificação de Solos (EMBRAPA, 1999).

A partir disso, as unidades vegetacionais são caracterizadas e distribuídas de maneiras diferenciadas conforme a cota altimétrica. Segundo Fernandes (1998), as unidades vegetacionais presentes na serra são: Arboreto Climático Estacional Caducifólio, abrangendo espécies da caatinga, presentes na base das vertentes da serra; o Arboreto Climático Estacional Semicaducifólia, 
e Arboreto Climático Estacional Perenifólia, ocupando as áreas com maior umidade e de relevo acidentado da serra, esta é a unidade que possui maior porte e adensamentos de suas copas, com características bastante semelhantes à da Mata Atlântica.

Por conseguinte, há um predomínio de espécies arbóreas, com áreas de cultivos de jaqueiras, abacateiros e, principalmente, da prática da bananicultura. Tendo em vista que a temperatura amena, a alta umidade, os altos índices pluviométricos e os solos férteis constituem-se em um grande atrativo populacional, um refúgio para o sertanejo, que foge das condições adversas encontradas em vários setores das depressões interplanálticas semiáridas nordestinas.

\section{METODOLOGIA}

Na presente pesquisa optou-se por utilizar a perspectiva holística e sistêmica ensejada na Análise Integrada do Ambiente de Souza (2000). Em seu estudo, Souza (2000) adaptou a Teoria Geossitêmica de Bertrand (1968) a qual propõe um sistema taxonômico e hierárquico das paisagens com uma tipologia às ordens taxonômicas do relevo e a Ecodinâmica de Tricart (1977) para regiões naturais do Estado do Ceará, definindo com isso, as unidades geoambientais, bem como, suas características dominantes, grau de vulnerabilidade, estado de conservação e capacidade de suporte frente ao uso e ocupação.

Dentre os procedimentos operacionais executados, utilizou-se de levantamento de dados bibliográficos e cartográficos secundários em órgãos pertinentes, além de materiais produzidos sobre a temática abordada tais como: artigos, monografias, dissertações, teses, relatórios técnicos; livros; revistas cientificas; periódicos da capes.

Para o desenvolvimento do estudo, foram utilizadas imagens digitais do sensor Thematic Mapper (TM) do satélite Landsat 5, obtidas no site do Instituto Nacional de Pesquisas EspaciaisINPE em formato geotiff com projeção/datum UTM/SAD-69 para os anos de 1991 e 2001. Vale ressaltar que o satélite Landsat 5 possui uma resolução espacial de 30x30 metros. Também foi utilizada imagem do satélite Landsat 8 , a mesma também possui uma resolução de $30 \mathrm{~m}$, com data de passagem em 21/07/1991, 01/08/2001 (Landsat 5) e 08/08/2015 (Landsat 8) na órbita 217, ponto 63, compondo as imagens nas bandas 5,4,3. Com o intuito de uma melhor percepção do espaço trabalho utilizou-se a escala de 1: 200.000. Foram levados em consideração alguns critérios para a escolha das imagens utilizadas no mapeamento do Índice de vegetação, cujo o primeiro critério foi a disponibilidade das imagens. O segundo leva a qualidade das imagens e o terceiro o período da imagem, a partir da semelhança das quadras climáticas. 
Além disso, optou-se pelos softwares livres tais como: QGIS versão 2.14, um sistema livre de informação geográfica (SIG) para a confecção de um mapa e o SPRING 5.2.6 (Sistema de Processamento de Informações Georreferenciadas) para Windows (MS), desenvolvido pelo Instituto Nacional de Pesquisas Espaciais -INPE, São José dos Campos, SP, Brasil. As Bases cartográficas utilizadas foram disponibilizadas pelo Instituto de Pesquisa e Estratégia Econômica do CearáIPECE, Fundação Cearense de Meteorologia e Recursos Hídricos - FUNCEME, Instituto Brasileiro de Geografia e Estatística -IBGE.

Dentro desse contexto, no presente trabalho foi analisado o estado da cobertura vegetal na Serra de Maranguape, utilizando-se a análise integrada da paisagem para observar seu estado de conservação, verificando assim as áreas de degradação ou recuperação da vegetação. Para chegar aos resultados, utilizou-se o NDVI - Normalized Difference Vegetation Index ou Índice de Vegetação da Diferença Normalizada.

Existem inúmeros índices de vegetação, mas atualmente o NDVI é o mais usual e possui o maior número de aplicações em pesquisas. O índice é uma combinação de bandas espectrais que são captadas por sensores, muitos dos casos são utilizados satélites. Esses sensores são capazes de reconhecer pigmentos das folhas tratados na região do visível. Dessa forma, o NDVI torna-se um eficiente indicativo do estado da planta e a quantificação da vegetação, pois considera relevante a energia absorvida dos raios ultravioletas com a refletida na região e captada pelos sensores evidenciando as condições celulares.

\section{RESULTADOS E DISCUSSÃO}

Na análise da pluviometria dos anos de 1991, 2001 e 2015, levou-se consideração apenas o município de Maranguape, tendo em vista que a maior parte da serra se encontra compreendida no mesmo. Dessa forma, verifica-se a concentração do período chuvoso nos primeiros 4 meses do ano, representando quase que o total de precipitação anual. No ano de 1991, o total pluviométrico anual foi de 973,4 mm/ano. Em 2001, o média anual ficou em $863 \mathrm{~mm} / \mathrm{ano}$, dos anos analisados ficando muito abaixo do esperado para região, porém, em 2015, a o total precipitado foi de $941,1 \mathrm{~mm} / \mathrm{ano}$.

No Estado do Ceará, o regime térmico, contrariamente, no que se observa com o ritmo das chuvas, é marcado por pequenas variações e por uma maior regularidade. Durante todo o ano, as temperaturas têm valores elevados, com médias em torno de $26^{\circ} \mathrm{C}$ a $29^{\circ} \mathrm{C}$. No entanto, nos relevos serranos, há uma amenização sensível das condições térmicas, apresentando valores entre $21^{\circ} \mathrm{C}$ e $23^{\circ} \mathrm{C}$. As amplitudes térmicas não ultrapassam $5^{\circ} \mathrm{C}$ (SOUZA, 2000). 


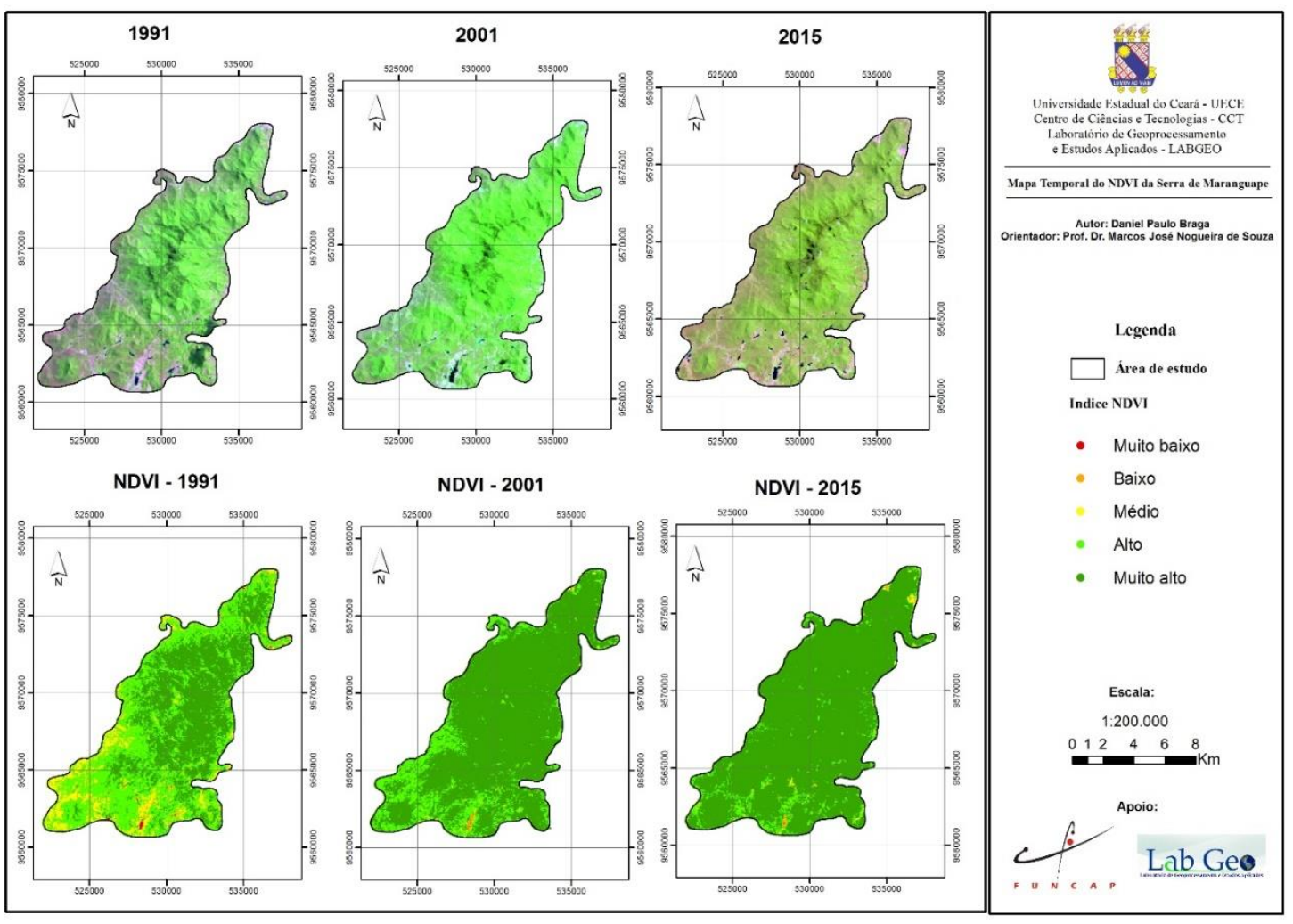

Figura 02: Mapa Temporal do NDVI da Serra de Maranguape.

Fonte: Elaborado pelo autor, 2016.

De acordo com a imagem acima o NDVI dos anos de 1991, 2001 e 2015 pode ser interpretado pela relação existente da biomassa, pois quanto maior for a biomassa, mais alto será o Índice do NDVI e, consequentemente significa que a vegetação está mais conservada. Assim, a partir da consulta bibliográfica, a verificação de imagens de satélites e a elaboração do nível de vegetação, constata-se uma significativa mudança no índice de vegetação (Figura 02).

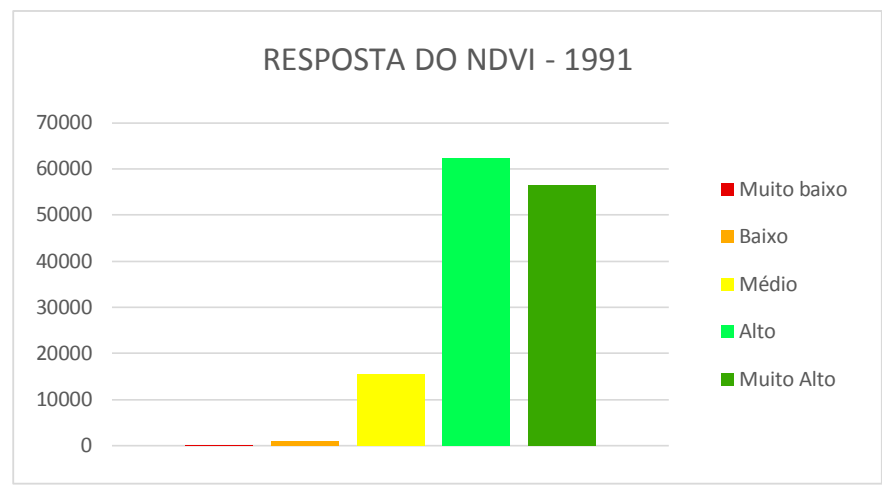

Gráfico 01: Gráfico das classes do NDVI do ano de 1991.

Fonte: Elaborado pelo autor, 2016.

No Gráfico 01 nota-se que no ano de 1991 o nível de cobertura vegetal classificado como Alto e Muito Alto estavam equivalentes, e o nível de vegetação Médio era bem representado, já os níveis Baixo e Muito Baixo são quase inexpressivos. 
Esse equilíbrio entre os índices Alto e Muito Alto estão associados com a precipitação registrada com uma média total de 973,4 mm/ano (Gráfico 02), com chuvas concentradas nos meses de fevereiro-maio, tendo seu pico no mês de março com 317,4 mm, e no segundo semestre tem-se um período de estiagem, refletindo na menor biomassa.

Além do que, nessa década foi verificado que na Serra de Maranguape havia sim uma tendência a retirada da cobertura vegetal. Segundo Souza e Oliveira (2006), a cobertura vegetal primária está fortemente descaracterizada em função do uso descontrolado para várias práticas, seja ela do tipo agrícola, seja imperatória ou pastoril.

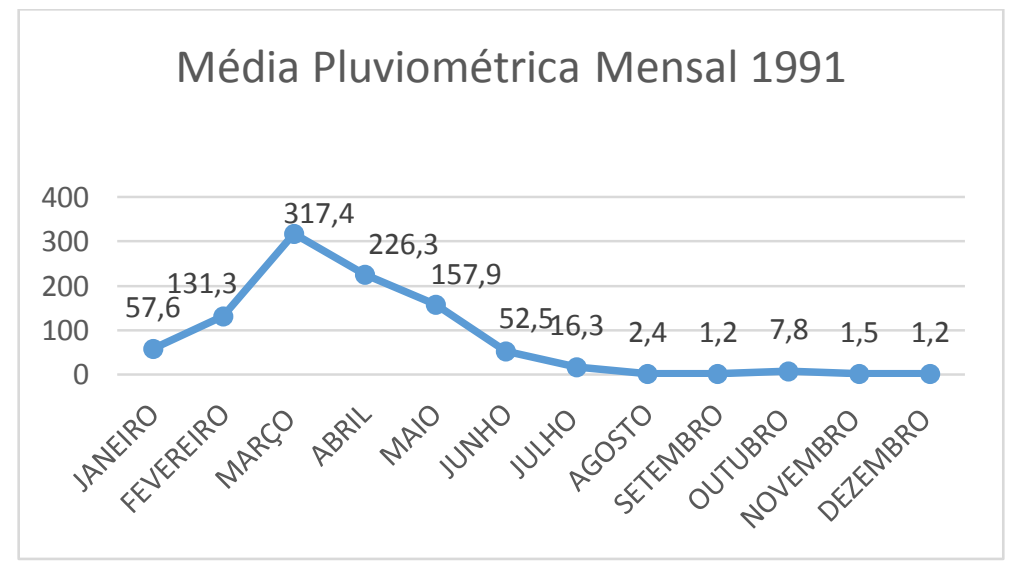

Gráfico 02: Média Pluviométrica Mensal do ano de 1991.

Fonte: FUNCEME. Adaptado: Autor, 2016

Em 2001, através da análise do NDVI e de imagem de satélites, é notável uma mudança nos níveis de vegetação, sugerindo assim uma recuperação nas áreas onde foi constatado outrora Médio e Alto (Gráfico 03). Dessa forma, o índice Muito Alto obteve um aumento bem expressivo. Já os níveis Baixo e Muito Baixo continuaram quase inexpressivos.

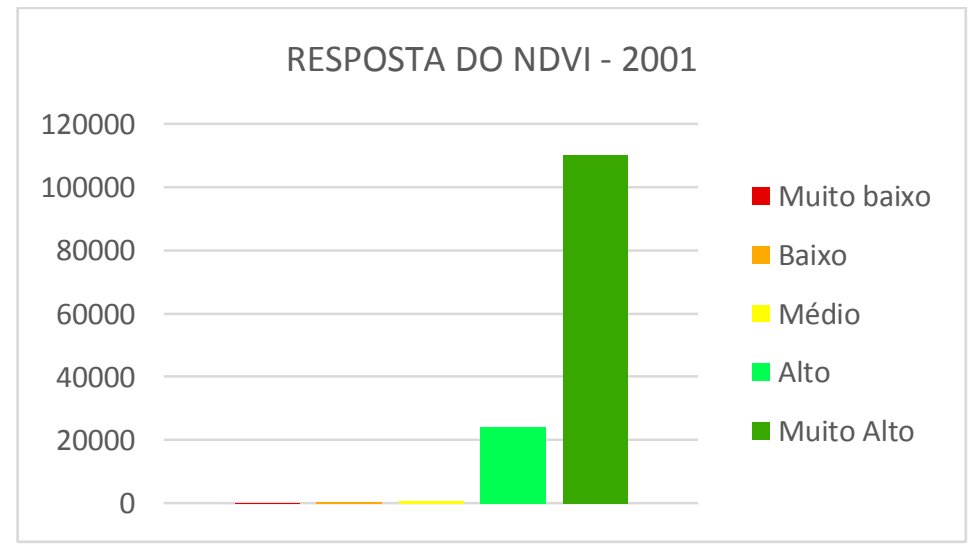

Gráfico 03: Gráfico das classes do NDVI de 2001.

Fonte: Elaborado pelo Autor, 2016.

No ano de 2001 vimos claramente uma recuperação e uma resposta do espectro correspondente a vegetação mais intensa, fato este, que teve influência das chuvas do primeiro 
semestre se prolongarem até o mês de junho registrando 104,3 mm, apesar da média total ter sido 863,0 mm/ano (Gráfico 04).

Vale salientar que podendo indicar que as atividades ali presentes antes como as agropastoris estavam sendo continuamente abandonadas. Essa parcela da população poderia está deixando suas atividades para irem em busca de empregos na área industrial, tendo em vista que em 1984 o município de Maracanaú foi emancipado do município de Maranguape. Também foi criado o Distrito Industrial de Fortaleza através da política de industrialização da Superintendência de Desenvolvimento do Nordeste (SUDENE), onde diversas indústrias se instalaram para compor o novo quadro da dinâmica e expansão da economia cearense.

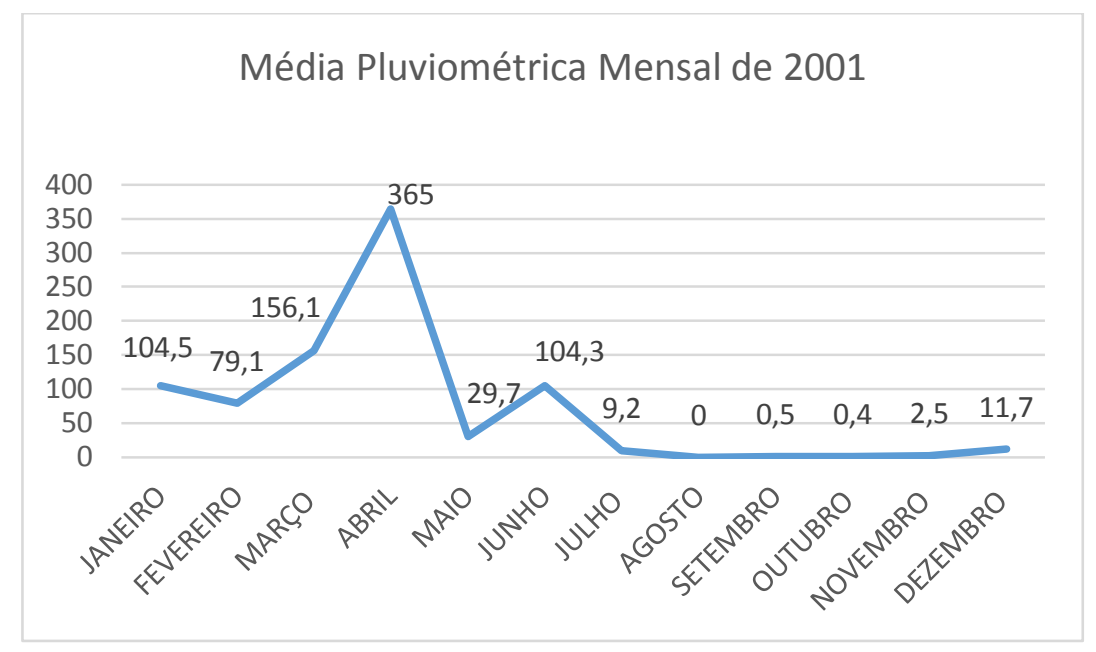

Gráfico 04: Média Pluviométrica Mensal do ano de 2001.

Fonte: FUNCEME. Elaboração: Autor, 2016.

Em 2015, houve um pequeno aumento do índice Médio de vegetação, segundo as análises, chegamos à conclusão que isto é resultante da implantação de duas áreas de mineração (Gráfico 05). Já o índice Alto continuou em declínio e o Muito Alto mostra-se em crescente aumento e, em relação a 1991, percebe-se uma recuperação de áreas antes ocupadas pela agricultura.

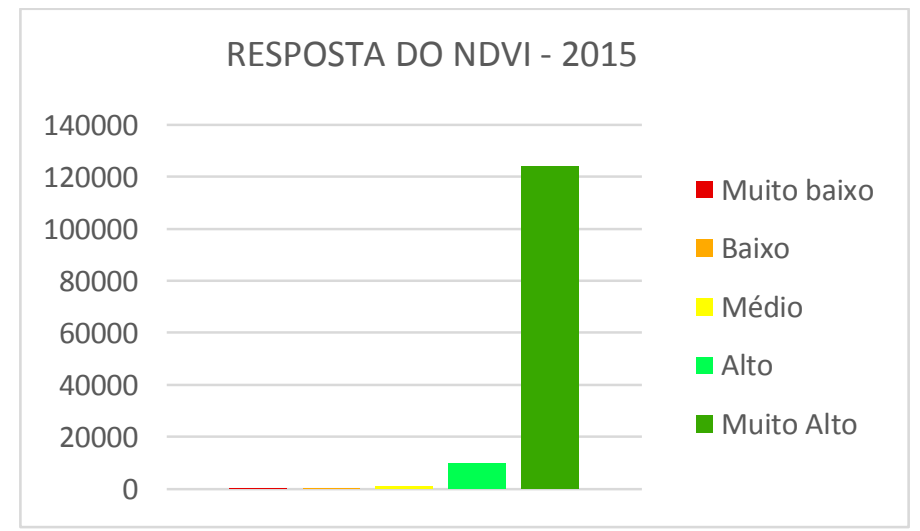

Gráfico 05: Gráfico das classes do NDVI de 2015.

Fonte: Elaborado pelo Autor, 2016. 
A recuperação da resposta do espectro correspondente a vegetação mais intensa continuou no ano de 2015, fato que está diretamente associado a maior precipitação com uma média total de 941,1 mm/ano, associado a melhor distribuição da precipitação ao longo do primeiro semestre, que se estendeu até o mês de julho que registrou 119,6 mm (Gráfico 06).

Essa distribuição da chuva até início do segundo semestre tem grande importância, porque significa que a vegetação ficará com menos tempo sem água até o próximo período chuvoso e, portanto, nesse segundo semestre a vegetação estará menos sujeita ao estresse hídrico, que reflete diretamente na maior ou menor presença de biomassa no índice de NDVI.

Ademais, em 2015, porém foi constatado uma grande clareira, uma grande área degradada, na porção da serra que compreende o município de Maracanaú e de Caucaia. Através de visitas de campo, visualizando a instalação de duas áreas de mineração uma em Maracanaú e outra Caucaia.

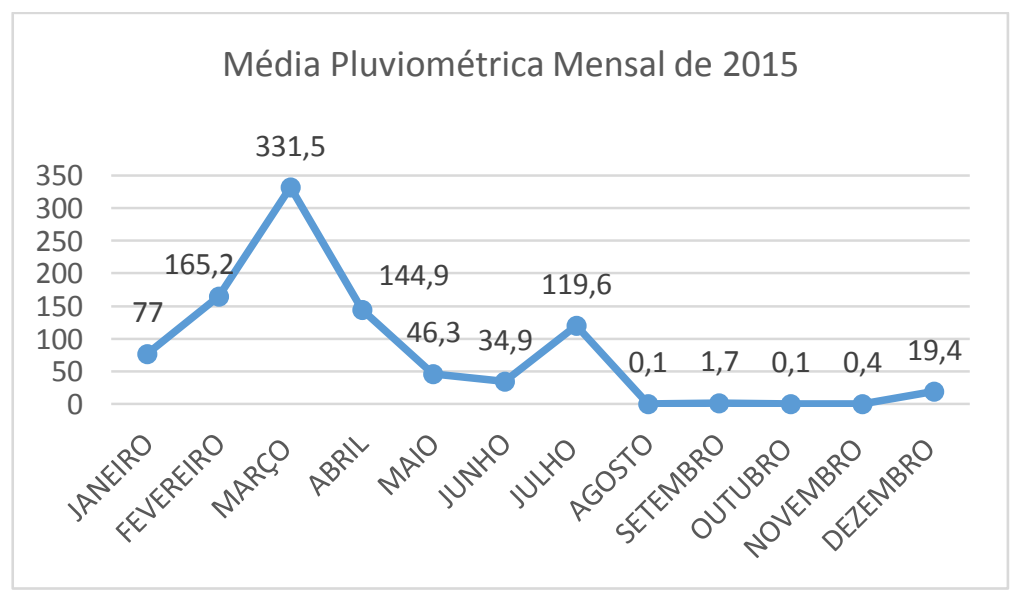

Gráfico 06: Média Pluviométrica Mensal do ano de 2015.

Fonte: FUNCEME. Elaboração: Autor, 2016.

Dessa forma, é nítido que a técnica do NDVI possibilitou de maneira satisfatória realizar uma análise temporal do estado de conservação da Serra de Maranguape através da presença de maior ou menor presença de biomassa.

\section{CONSIDERAÇÕES FINAIS}

Conclui-se que a Serra de Maranguape é um importante enclave úmido e se destaca das demais regiões do estado por possui características de solo, clima, umidade, hidrografia e vegetação diferenciados.

Dessa forma, chega-se à conclusão que a técnica do NDVI não possibilitou de maneira satisfatória avaliar o estado de conservação da Serra de Maranguape, devido ao índice levar em consideração a critério da presença de maior ou menor biomassa. A mesma pode nos retornar 
valores imprecisos, devido a uma grande parte da vegetação que, em períodos de estiagem perdem suas folhas para a retenção de umidade, porém em períodos chuvosos retornam ao estado original com folhas de coloração esverdeada.

Portanto, a preocupação com a conservação e/ou preservação da cobertura vegetal tem sido motivo de debates e discussões sobre as abordagens técnicas, científicas e a legislação de proteção das florestas, inclusive há a delimitação de Áreas de Preservação Ambiental, concluindo-se que a cobertura vegetal é fundamental para o equilíbrio da biodiversidade.

Devido as condições de vegetação que o semiárido oferece, não foi possível chegar ao resultado precisos do estado de conservação da Serra de Maranguape através do NDVI, porém foram detectadas áreas de mineração em expansão que precisam ser analisadas, junto aos impactos que ambientais e sociais.

Recebido em: $\mathrm{xx} / \mathrm{xx} / \mathrm{xxxx}$

Aceito para publicação em: xx/xx/xxxx

\section{REFERÊNCIAS}

ARRUDA, Luciene Vieira de. Serra de Maranguape - CE: Ecodinâmica da paisagem e implicações socioambientais. Dissertação de Mestrado. Fortaleza, Universidade Estadual do Ceará, 2001.

BERTALANFFY, L. V. Teoria Geral dos Sistemas. Tradução: Francisco M. Guimarães. $2^{a}$ ed. Petrópolis: Vozes, 1975.

BERTRAND, G. - 1968. Paisagem e Geografia física global: Esboço Metodológico. In Caderno de Ciências da Terra, N. 8, p. 141-152. R. RA’E GA. Curitiba: Editora da UFPR, 2004.

CEARÁ. Zoneamento ambiental e plano de manejo da Área de Proteção Ambiental (APA) da Serra de Maranguape (CE). Fortaleza: SEMACE, 2002.

CORDEIRO, A. M. Análise Socioambiental da sub-bacia hidrográfica do rio Pirapora Maranguape/Ceará, como subsídio ao planejamento territorial e à gestão ambiental. 2013. 166p. Dissertação (Mestrado em Geografia) - Universidade Estadual do Ceará. Fortaleza.

LIMA, Denis Barbosa. Análise temporal da cobertura e uso da terra como subsídio ao estudo de degradação ambiental da serra da Meruoca - Ceará. 2014. 156p. Dissertação (Mestrado em Geografia) - Universidade Estadual do Ceará. Fortaleza.

Séries Históricas. Fundação Cearense de Meteorologia e Recursos Hídricos (FUCEME). Disponível em: 〈http://www.funceme.br/produtos/script/chuvas>. Acesso em 28 de março de 2012. 
SOUZA, Guilherme Marques. Modelagem ambiental para a delimitação de brejos de altitude com estudo de casos para os maciços da Aratanha, Maranguape, Juá e Conceição - CE. Fortaleza. 2014. N pag. Dissertação de Mestrado. Programa de Pós-Graduação em Geografia, Fortaleza, 2014. SOUZA, M.J.N. 2005. Compartimentação Geoambiental do Ceará. In: Silva, J.B. et al. (Orgs.). Ceará: um novo olhar geográfico. Edições Demócrito Rocha, Fortaleza - CE. pp.127-140. OLIVEIRA. V. P. Os Enclaves Úmidos e Sub-Úmidos do Semiárido do Nordeste Brasileiro. Fortaleza, 2006. p. 85-102.

et al. Diagnóstico Geoambiental do Município de Fortaleza: subsídios ao macrozoneamento ambiental e à revisão do Plano Diretor Participativo - PDPFor. Fortaleza: Prefeitura Municipal de Fortaleza, 2009.

SOTCHAVA, V. B. O estudo dos geossistemas, Métodos em questão. São Paulo: USP. Instituto de Geografia. Boletim Paulista de Geografia, n. 6, 1977.

TRICART, J. Ecodinâmica. Rio de Janeiro: IBGE/SUPREM, 1977.

TROPPMAIR, H.; GALINA, M. H. Geossistemas. Mercator, v. 10, p. 79-89, Ceará, 2006.

Recebido em: 14/08/2016

Aceito para publicação em: 01/10/2016 